International Journal on Integrating Technology in Education (IJITE) Vol.7, No.3, September 2018

\title{
STAKEHOLDERS' DILEMMA AND ACADEMIC LEADERSHIP ON THE DIFFERENT COMPUTING DISCIPLINES
}

\author{
Franklin Wabwoba and Alice Wechuli Nambiro \\ Department Information Technology, Kibabii University, Bungoma, Kenya
}

\begin{abstract}
There is significant overlap between the uniqueness of the disciplines that has complicated trainers, learners and business community's choice between the different disciplines. As computing has rapidly evolved its different disciplines has equally expanded in the academic community. The distinction between disciplines by the trainers is purposed to provide unique skills to serve unique needs of employers and society needs. For the business community to receive the best from the products of the programs therefore, it needs to understand what each of the different types of programs provides to meet their needs. This paper presents the results of a survey to determine if stakeholders were able to differentiate between computing disciplines and the level of academic leadership available. The findings of this paper make it clearer the distinct uniqueness of the different computing disciplines. The study found out the computing disciplines are each unique to themselves although there exists an overlap over the content covered. The study established that the stakeholders are not very clear of the difference between the computing disciplines. It also established that some universities have while others do not have academic leadership in the computing disciplines. When the practitioners are very clear on the differences between the different computing disciplines they are most likely to choose the correct employee, training as well as provide the correct training of the relevant discipline. The implication of the findings being that most likely organizations may not be receiving to best returns from the computing human resource employed as a result of hiring those not best suited for their tasks. Based on the findings of this research, further research can be undertaken on the various curriculum offered by universities to ascertain whether the unique computing disciplines are apparent in them.
\end{abstract}

\section{KEYWORDS}

Unique computing disciplines, Industry computing perspective, Learners computing perspective, Trainers computing perspective

\section{INTRODUCTION}

As computing has rapidly evolved, so have attempts to classify the computing disciplines into distinct disciplines or career paths [1] in the academic circles. Computing has evolved and transverses many different areas of the economy. The development of the disciplines in the different economies is becoming very unique to the areas however sharing a lot between related disciplines. Today, most of the technological systems around us making use of computing applications and Technology has become part of our everyday life [2]. As more and more computing infrastructure is being adopted by businesses and organizations, there is increasing demand for graduates with more appropriate applied and theoretical knowledge to manage the infrastructure [1]. This requires stakeholders in the computing sector to be able to train or employ personnel who are able deploy and utilise the computing skills well. Therefore, for educators, the ability to use modern technology turns out to be very essential in preparing computing graduates for competition in a global workplace [3] since modern technology is driven by computing. 
International Journal on Integrating Technology in Education (IJITE) Vol.7, No.3, September 2018

\subsection{Evolution Of COMPuting Disciplines}

The growth of the computing fields in Kenya has taken the same trend just like the rest of the world up to the current 2010s.

\subsubsection{BEFORE THE 1990S}

During this time period, very few people in Kenya understood clearly what Computing was all about. It was a preserve of the very few who were luck to learn some programming in mathematics related programmes. For the rest of the world two computing fields arose in the $60 \mathrm{~s}$ namely computer science (CS) and information systems (IS) [4]. A closely related discipline to computing, during the same era, was electrical engineering (EE) that aided their operations to a large extent [1]. In the 1960s, Computer Science in Kenya was treated more as a mathematics fields while Information Systems were treat more as a business discipline.

By the early 1970s, for one to take some computer courses in Kenya emphasis was put on ones analytical skills hence good performance in mathematics being a key pre-requisite. Great emphasis in the teaching of computing courses was on programming. The kind of rigour that was needed to develop a good program and emphasis to follow given principals gradually gave rise to Software Engineering in the late 1980s. Shortly after this the realization that the computer hardware needed to be programmed at machine level and the developments in the electronic field led to the adoption of computer engineering as a field of its own that had already begun in developed world. This was further reinforced the demands of the stakeholder community consuming the computer science and electrical engineering products. These developments happened too fast that to many people outside of the computing and engineering community distinction between electrical engineering and computer engineering remained unclear.

\subsubsection{SigNifiCANT DEVELOPMENTS OF THE 1990S}

In the early 1990s, computing became a recognised discipline of study independent in Kenya. The country quickly adopted the Computer Science, Information Systems and Computer Engineering/ Technology as distinct fields of study. However, very few institutions offered training as computing was still a myth in the minds of many Kenyans. During this same era in the rest of the world, proponents asserted that computing was a legitimate discipline with its own identity, while critics dismissed it as a vocational specialty for technicians, a research platform for mathematicians or a pseudo-discipline for computer programmers with its own developed considerable body of research, knowledge, and innovation that spanned the range from theory to practice, and the controversy about its legitimacy died [4]. During the 1990s, computer science department begun to be established in many Kenyan training institutions of high learning and faced unprecedented demands. Industry needs for qualified computer science graduates especially the finance sector exceeded supply by a large factor in Kenya. At this time any person who had any little knowledge of computing was quickly absorbed without regard of whether the skills that he/she had were the once need by the industry. Many had to learn the hard way on the on the job training.

By the late 1990s, the ability for a networked computer environment introduced a new challenge to the Kenya computing Because of the expanded role of computers, organizations had more information available than ever before and organizational processes were increasingly enabled by computing technology [1]. The problems of managing information became extremely complex, and the challenges of making proper use of information and technology to support organizational efficiency and effectiveness became crucial. In order to meet these challenges, the Kenyan community adopted the Information Systems and Information Technology as distinct discipline which had already developed in other parts of the world. 
International Journal on Integrating Technology in Education (IJITE) Vol.7, No.3, September 2018

Collectively, these developments reshaped the landscape of the computing fields in Kenya. This maturation, evolution and adoption created a greater range of possibilities for students and educational institutions. The middle portion of Figure 2.1 shows how prospective students in this era might have perceived the range of choices available to them.

The post-1990s world presented meaningful choices: computer science, software engineering, and computer engineering each including their own perspective on software development with CE having software attention focused on hardware devices, SE having software attention on software that satisfies robust real-world requirements and CS having software attention on wide range of computing problems and applications. On the other hand, the IT and IS fields focused on software and hardware but emphasizing they use technology as critical instruments for addressing organizational needs.

Due to the diverse needs by the diverse user community of computing arising uniquely in Kenya and the rest of the world, it become necessary for programs to be developed that uniquely provide for the skills to fulfill the needs. This gave rise to the different computing fields being offered. According to the Association of Computing Machines (ACM), (2008), five primary computing fields namely Computer Science (CS), Information Technology (IT), Information Systems (IS), Computer Engineering (CE), and Software Engineering (SE) emerged and all the five were adopted in Kenya.

\subsubsection{AFTER THE 2010S}

After the 2010, a sixth primary computing discipline Information and Communication Technology (ICT) emerged. The new discipline seems to be converging all the three thematic families that were seen in the pre-1990s into one thematic family in the 2010s. The ICT family is developing its philosophy drawing majorly from the communication, information and technology philosophies.

Information Communication Technology (ICT) is an umbrella term used to encompass all rapidly emerging, evolving and converging computer, software, networking, telecommunications, Internet, programming and information systems technologies. Historically, many of these disciplines developed separately, in different companies, departments and R\&D groups, and at different times. With rapid improvements in computer processing power, networking technology advances, programming interface improvements, widespread adoption of Internet Protocols, integration into organizational strategic operations, and improved workforce and user competencies, the disciplines are however rapidly converging. It arises out of two main disciplines of Information Technology and Communication Technology. This arises when looked at from the Information Technology perspective as concerned with the computer itself, including the processes of storing, retrieving or manipulating data where computer hardware and software is included. Also communications technology being perceived to refer to how computers, or any machines, communicate with each other or with people where people or machines may not all be in the same location. This therefore includes the processes of transferring data from one machine to another e.g. using radio, telephone equipment, fax machines, video, email or other means.

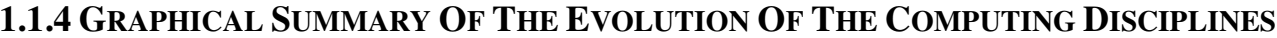

The evolution of the computing disciplines discussed above can be summarized graphically as presented in Figure 1. The general trend is that of converging into one closed up major family. 

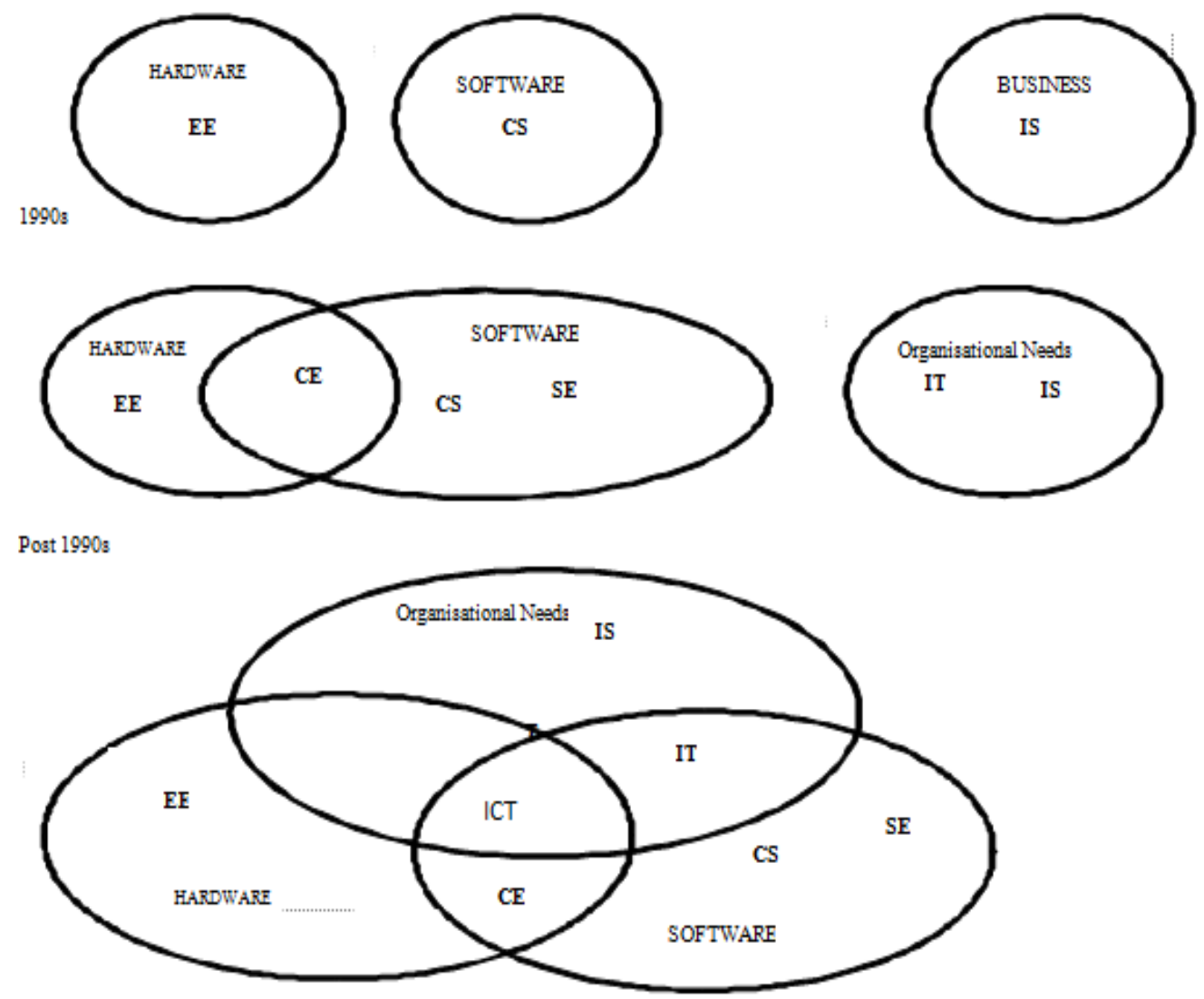

Figure 1: Computing discipline evolution up to the 2010s

Adapted from [8] computing curricula 2005 - The overview report

When prospective students surveyed the choices of computing-related degree programs, most would have perceived the computing disciplines as shown in the Figure 1 during the different periods in time. The distance between the disciplines indicates how closely the people in those disciplines worked with each other.

\subsubsection{Problem Of The Study}

Computing is a relatively new discipline of study that is expanding rapidly. There is significant overlap between academic degree programs offered within it that is complicating students' and the business community's choices as to which degree program they should choose from. To a large extend this has ended up with people in careers for which they are not best equipped for. It is also not very clear if there is relevant appropriate and adequate leadership within the computing disciplines training. Employers have complained of graduates they employ not being able to deliver, however, one wonders whether they are employing the right graduates for the jobs. To gain the best out of skilled human beings, it calls for appropriate alignment of the skills possessed and the job hired to. The study sought to establish if the employing community, trainers as well as the trainees were aware of the differences between the computing disciplines and the skills each offers and if there was clear leadership for the training within the different computing disciplines. 
International Journal on Integrating Technology in Education (IJITE) Vol.7, No.3, September 2018

\subsubsection{Objectives of the study}

a) Review the uniqueness of the computing disciplines

b) Determine the stakeholders understanding of the skills for each of the computing disciplines

c) Assess the leadership capacity for computing disciplines in the universities

\section{Methodology}

Document analysis based on secondary data as well as desktop survey was conducted to review the uniqueness of the different computing disciplines and partly to ascertain leadership for the computing programmes. Survey was employed to further establish primary data with regard to different computing disciplines' leadership and the stakeholders understanding of the disciplines' uniqueness. In the months of November and December 2017, voluntary responses were solicited from 35 lecturers teaching programs in the computing disciplines from 7 chartered universities, 30 fourth year undergraduate students pursuing programmes in the computing disciplines from 5 chartered universities and 30 ICT management staff from 15 firms that have running ICT units in Kenya to establish their understanding of the uniqueness of the computing disciplines. The chartered universities websites were surveyed to find those that had displayed qualifications of their staff to establish the level of leadership. A total of 17 public chartered universities and 7 private chartered universities were then purposively sampled using the criteria of having displayed the computing lecturers' qualification on the website giving a $48.98 \%$ representation of the all chartered universities in the country. The detailed particulars are a given below

$\begin{array}{llll}\text { Category of university } & \text { Total } & \text { Sampled } & \text { Percentage } \\ \text { Public Chartered Universities } & 31 & 17 & 54.83 \% \\ \text { Private Chartered Universities } & 18 & 7 & 38.89 \% \\ \text { Total } & 49 & 24 & 48.98 \%\end{array}$

\section{Discussion Of The Findings Of The Study}

The finding of the study in line with the uniqueness of the computing disciplines, the understanding by stakeholders and leadership for the same is discussed in the sections A to C.

\subsection{UNIQUENESS OF COMPUTING DISCIPLINES}

Despite the fact that computing disciplines have a lot in common that makes it had to differentiate them, they at the same time have each their own uniqueness. It was analysed to establish the strong and weak bias topics for each of the five disciplines of computing. Courses were considered to be a strong area of bias if it had as sum of minimum weight and maximum weight of 7 and above. On the other hand an area was considered to be of weak bias to the discipline if sum of minimum weight and maximum weight was less than 3 . Using this criterion the strong and weak areas of bias for each computing discipline were considered to be as indicated in the discussion that follows. Table 1 gives the most agreed on weightings by most professionals in computing and professional bodies such as Association of Computing Machinery, IEEE and Association of Information Technology. 
International Journal on Integrating Technology in Education (IJITE) Vol.7, No.3, September 2018

Table 1: Comparative weight of computing topics across the five kinds of degrees

\begin{tabular}{|c|c|c|c|c|c|c|c|c|c|c|}
\hline \multirow[b]{2}{*}{ Knowledge area } & \multicolumn{2}{|c|}{$C E$} & \multicolumn{2}{|c|}{$\operatorname{cs}$} & \multicolumn{2}{|c|}{ IS } & \multicolumn{2}{|c|}{ IT } & \multicolumn{2}{|c|}{ SE } \\
\hline & 具 & 흘 & 具 & 흘 & 具 & 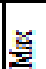 & 具 & 흘 & 是 & $\underline{E}$ \\
\hline Pro gramming Fundamentals & 4 & 4 & 4 & 5 & 2 & 4 & 2 & 4 & 5 & 5 \\
\hline Integrative Pro gramming & 0 & 2 & 1 & 3 & 2 & 4 & 3 & 5 & 1 & 3 \\
\hline Algorithms and Complexity & 2 & 4 & 4 & 5 & $\overline{1}$ & 2 & 1 & 2 & 3 & 4 \\
\hline Computer Architecture and Organization & 5 & 5 & 2 & 4 & 1 & 2 & 1 & 2 & 2 & 4 \\
\hline Operating Systems Principles and Design & 2 & 5 & 3 & 5 & $\frac{1}{1}$ & $\overline{1}$ & $\frac{1}{1}$ & 2 & 3 & 4 \\
\hline Operating Systems Configuration and Use & 2 & 3 & 2 & 4 & 2 & 3 & 3 & 5 & 2 & 4 \\
\hline Net Centric Principles and Design & $\overline{1}$ & 3 & 2 & 4 & $\overline{1}$ & 3 & 3 & 4 & 2 & 4 \\
\hline Net Centric Use and Confi guration & 1 & 2 & 2 & 3 & $\frac{1}{2}$ & 4 & 4 & 5 & 2 & 3 \\
\hline Platform technolo gies & 0 & $\overline{1}$ & 0 & 2 & $\overline{1}$ & 3 & 2 & 4 & 0 & 3 \\
\hline Theory of pro gramming lan guages & 1 & 2 & 3 & 5 & 0 & 1 & 0 & 1 & 2 & 4 \\
\hline Human Computer Interaction. & 2 & 5 & 2 & 4 & 2 & 5 & 4 & 5 & 3 & 5 \\
\hline Graphics and visualization & 1 & 3 & 1 & 5 & $\overline{1}$ & 1 & 0 & 1 & 1 & 3 \\
\hline Intelliaent Systems & 1 & 3 & 2 & 5 & $\frac{1}{1}$ & 1 & 0 & 0 & 0 & 0 \\
\hline Information Management Theory & 1 & 3 & $\overline{2}$ & 5 & $\frac{1}{1}$ & 3 & 1 & 1 & 2 & 5 \\
\hline Information Management practice & 1 & 2 & $\overline{1}$ & 4 & 4 & 5 & 3 & 4 & $\overline{1}$ & 4 \\
\hline Numerical Methods & 0 & 2 & 5 & 5 & 0 & 0 & 0 & 0 & 0 & 0 \\
\hline Legal/Professional / Ethics / Society & 2 & $\overline{5}$ & 2 & 4 & 2 & 5 & 2 & 4 & 2 & 5 \\
\hline Information Systems Development & 0 & 2 & 0 & 2 & 5 & 5 & $\overline{1}$ & 3 & 2 & 4 \\
\hline Analysis Business Requirements & 0 & $\overline{1}$ & 0 & $\overline{1}$ & 5 & 5 & 1 & 2 & $\overline{1}$ & 3 \\
\hline E-business & 0 & 0 & 0 & 0 & 4 & 5 & 1 & 2 & 0 & 3 \\
\hline Analysis Business Requirements of technical requirements & 2 & 5 & 2 & 4 & 2 & 4 & 3 & 5 & 3 & 5 \\
\hline Engineering foundations for software en gineering & $\overline{1}$ & 2 & $\overline{1}$ & 2 & $\overline{1}$ & 1 & 0 & 0 & 2 & 5 \\
\hline Engineering economics for software en pineering & 1 & 3 & 0 & $\overline{1}$ & 1 & 2 & 0 & 1 & 2 & 3 \\
\hline Software modeling and analysis & 1 & 3 & 2 & 3 & 3 & 3 & 1 & 3 & 4 & 5 \\
\hline Software design & 2 & 4 & 3 & 5 & 1 & 3 & 1 & 2 & 5 & 5 \\
\hline Software verification and validation & $\overline{1}$ & 3 & 1 & 2 & 1 & 2 & 1 & 2 & 4 & 5 \\
\hline Software evolution (maintenance) & 1 & 3 & 1 & $\overline{1}$ & 1 & 2 & 1 & 2 & 2 & 4 \\
\hline Software process & 1 & I & 1 & 2 & 1 & 2 & I & I & 2 & 5 \\
\hline Software quality & 1 & 2 & 1 & 2 & 1 & 2 & 1 & 2 & 2 & 4 \\
\hline Computer systems en pineering & 5 & 5 & $\frac{1}{1}$ & 2 & 0 & $\overline{0}$ & 0 & 0 & 2 & 3 \\
\hline Digital logic & 5 & 5 & 2 & 3 & 1 & 1 & 1 & 1 & $\overline{0}$ & 3 \\
\hline Embedded systems & 2 & 5 & $\overline{0}$ & 3 & 0 & $\frac{1}{0}$ & 0 & $\frac{1}{1}$ & 0 & 4 \\
\hline Distributed systems & 3 & 5 & 1 & 3 & 2 & 4 & 1 & 3 & 2 & 4 \\
\hline Security: Issues and principles & 2 & 3 & $\frac{1}{1}$ & 4 & 2 & 3 & $\frac{1}{1}$ & 3 & $\overline{1}$ & 3 \\
\hline Security: Implementation and management & $\overline{1}$ & 2 & $\frac{1}{1}$ & 3 & $\overline{1}$ & 3 & 3 & 5 & $\frac{1}{1}$ & 3 \\
\hline Systems administration & 1 & 2 & 1 & 1 & 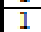 & 3 & 3 & 5 & 1 & 2 \\
\hline Management of In formation systems organisation & 0 & $\overline{0}$ & 0 & 0 & 3 & 5 & 0 & 0 & 0 & 0 \\
\hline Systems integration & 1 & 4 & 1 & 2 & 1 & 4 & 4 & 5 & 1 & 4 \\
\hline Di pital media development & 0 & 2 & 0 & $\overline{1}$ & 1 & 2 & 3 & 5 & 0 & 1 \\
\hline Technical support & 0 & 1 & 0 & 1 & 1 & 3 & 5 & 5 & 0 & 1 \\
\hline
\end{tabular}

In general based on the analysis of a number of professional documents with regard to the computing fields and table 1 above, it was established that though the different disciplines of computing share most courses, the weighting on each is different.

\subsubsection{COMPUTER ENGINEERING}

From table 1 it may be considered that training or curriculum in computer engineering had a strong bias towards Programming Fundamentals, Computer Architecture and Organisation, Operating Systems Principles and Design, Computer systems engineering, legal / Professional / Ethics / Society, Analysis Business Requirements of technical requirements, Digital logic and Distributed systems. At the same time such a curriculum or training had a weak bias in the areas of Platform technologies, Integrative Programming, Numerical Methods, Information Systems Development, Analysis Business Requirements, E-business, Software process, Management of Information systems organisation, Digital media development and Technical support.

Computer engineering is concerned with the design and construction of computers, and computer based systems [6]. It involves the study of hardware, software, communications, and the interaction between them. Its curriculum focuses on the theories, principles, and practices of relevant areas of traditional electrical engineering and mathematics, and applies them to the problems of designing computers and the many kinds of computer-based devices [7].

Computer engineering students study the design of digital hardware systems, including computers, communications systems, and devices used in computers. They also study software 
International Journal on Integrating Technology in Education (IJITE) Vol.7, No.3, September 2018

development with a focus on the software used within and between digital devices (not the software programs directly used by computer users). The emphasis of the curriculum is on hardware more than software, and it has a very strong engineering flavor.

Currently, a dominant area within computing engineering is embedded systems, the development of devices that have software components embedded in hardware. For example, devices such as cell phones, digital recorders, alarm systems, x-ray machines, and laser surgical tools all require integration of hardware and embedded software, and they are all the result of computer engineering.

Basically Computer Engineering designs hardware to implement communications systems, builds hardware devices such as iPods and integrates computer hardware and software [5] [1].

\subsubsection{COMPUTER SCIENCE}

With regard to Computer Science, the strong bias was on Programming Fundamentals, Algorithms and Complexity, Operating Systems Principles and Design, Theory of programming languages, Intelligent Systems, Information Management Theory, Numerical Methods and Software design as shown in table 1. The weak bias in such a curriculum or training was on Platform technologies, Information Systems Development, Analysis Business Requirements, Ebusiness, Engineering economics for software engineering, Software evolution (maintenance), Systems administration, Management of Information systems organisation, Digital media development and Technical support.

Computer science spans a wide range, from its theoretical and algorithmic foundations to cuttingedge developments in robotics, computer vision, intelligent systems, bioinformatics, and other exciting areas [8]. According to Lunt \& Ekstrom (2008) [4] the work of computer scientists as falling into three categories:

\section{(a) Developing effective ways to solve computing problems.}

For example, computer scientists develop the best possible ways to store information in databases, send data over networks, and display complex images. Their theoretical background allows them to determine the best performance possible, and their study of algorithms lets them develop new problem-solving approaches that provide better performance.

\section{(b) Devising new ways to use computers.}

Progress in the CS areas of networking, database, and human-computer-interface came together as the world-wide-web, which changed the world. Now, researchers are working to make robots be practical aides and even demonstrate intelligence, databases create new knowledge and, in general, use computers to do new things.

\section{(d) Designing and implementing software.}

Computer scientists take on challenging programming jobs. They also supervise other programmers, keeping them aware of new approaches.

(a)

Computer Science therefore is being uniquely identified as the computing disciplines that uses new theories to create cutting edge software, focusing on the theoretical aspects of technology, utilizing theory to research and design software solutions [5] [1] [6].

\subsubsection{INFORMATION SYSTEMS}

Based on table 1, Information Systems training or curriculum had a strong bias in Human Computer Interaction, Information Management practice, Legal/ Professional / Ethics / Society, 
International Journal on Integrating Technology in Education (IJITE) Vol.7, No.3, September 2018

Information Systems Development, Analysis Business Requirements, E-business and Management of Information systems organisation. Areas of weak bias in Information systems was in Operating Systems Principles and Design, Theory of programming languages, Graphics and visualization, Intelligent Systems, Numerical Methods, Engineering foundations for software engineering, Computer systems engineering, Digital logic and Embedded systems.

Students in Information Systems programs often referred to as Management Information Systems, study information systems and their use in business and other organizations [9]. Information systems specialists focus on integrating information technology solutions and business processes to meet the information needs of businesses and other enterprises, enabling them to achieve their objectives in an effective, efficient way. This discipline's perspective on information technology emphasizes information, and views technology as an instrument for generating, processing, and distributing information [4]. Professionals in the discipline are primarily concerned with the information that computer systems can provide to aid an enterprise in defining and achieving its goals, and the processes that an enterprise can implement or improve using information technology. They have a sound understanding of organizational principles and practices that enable them to serve as a bridge between the technical and management communities within an organization, enabling them to work in harmony to ensure that the organization has the information and the systems it needs to support its operations. Information systems professionals are also involved in designing technology-based organizational communication and collaboration systems.

Information Systems is the computing discipline that is business oriented and does combine knowledge of business and technology. It deals with selection computer systems to improve business processes and focuses on meeting the needs of users [10] [5] [1].

\subsubsection{INFORMATION TECHNOLOGY}

From table 1 it may be considered that training or curriculum in Information Technology had a strong bias in Integrative Programming, Operating Systems Configuration and Use, Net Centric Principles and Design, Net Centric Use and Configuration, Human Computer Interaction, Information Management practice, Analysis Business Requirements of technical requirements, Security: Implementation and management, Systems administration, Systems integration, Digital media development and Technical support. Its weak bias areas includes Theory of programming languages, Graphics and visualization, Intelligent Systems, Information Management Theory, Numerical Methods, Engineering foundations for software engineering, Engineering economics for software engineering, Software process, Computer systems engineering, Digital logic, Embedded systems and Management of Information systems organisation.

Information technology in a more focused sense refers to academic degree programs that prepare students to meet the technology needs of business, government, healthcare, schools, and other kinds of organizations [4]. It may be considered to be the study, design, development, implementation, support or management of computer-based information systems, particularly software applications and computer hardware [11]. It deals with the use of electronic computers and computer software to convert, store, protect process, transmit, and securely retrieve information [6]. According to the Association of Computing Machines (ACM), it focuses on issues that advocate for users and meeting users' needs within an organizational and the societal context through the selection, creation, application, integration and administration of computing technologies [12] [6]. Its emphasis hence is on the technology itself more than on the information it conveys.

Information Technology therefore tends to be more practical and applied. It deals with troubleshooting and designing applications. It applies the technology to solve practical problems therefore applying technical knowledge for product support [5] [1] [6]. 
International Journal on Integrating Technology in Education (IJITE) Vol.7, No.3, September 2018

\subsubsection{SOFTWARE ENGINEERING}

According to the findings in table 1, Software Engineering training or curriculum had a strong bias in Programming Fundamentals, Algorithms and Complexity, Operating Systems Principles and Design, Human Computer Interaction, Information Management Theory, Legal/ Professional / Ethics / Society, Analysis Business Requirements of technical requirements, Engineering foundations for software engineering, Software modeling and analysis, Software design, Software verification and validation and Software process. Training or curriculum in Software Engineering had weak bias in Management of Information systems organisation, Digital media development, Technical support, Intelligent Systems and Numerical Methods.

Software Engineering experts should be well versed with skills for designing and testing procedures for large-scale systems as well as management of large scale technological projects [4].

Software engineering is the discipline of developing and maintaining software systems that behave reliably and efficiently being affordable to develop and maintain while satisfy all the requirements that customers have defined for them [13]. However, Software engineering is different in character from other engineering disciplines due to both the intangible nature of software and the discontinuous nature of software operation. It seeks to integrate the principles of mathematics and computer science with the engineering practices developed for tangible and physical artifacts. Software Engineering is more focused on large-scale systems development, designing testing procedures for large-scale systems and managing large scale technological projects [5] [1].

\subsubsection{INFORMATION AND COMMUNICATION TECHNOLOGY}

This is the newest member of the computing family that is defining its philosophy. In many countries, there seems to be lack of acknowledgement of this emerging discipline as they argue that it is just but Information Technology. However, its philosophy seems to be defining its scope beyond that of IT.

Information and communication Technology (ICT) specialists focus on technology for communicating information thus technology solutions and business processes to meet the information communication needs of businesses and other enterprises, enabling them to achieve their objectives in an effective and efficient way. This discipline's perspective on information technology emphasizes communication, and views technology as an instrument for processing, and distributing information. Professionals in the discipline are primarily concerned with the communication of information that computerized systems can provide to aid an enterprise in defining and achieving its goals, and the communication processes that an enterprise can implement or improve using information technology.

\subsection{Stakeholders Understanding Of The Computing Disciplines In KenYa}

The understanding of computing disciplines by three stakeholders was sought and the findings are presented in sections 3.2.1, 3.2.2 and 3.3.3

\subsubsection{LECTURERS}

Thirty five lecturers having less than five years of working experience were interviewed with regard to their understanding of the uniqueness of the computing disciplines and the findings were as presented in table 2 . 
International Journal on Integrating Technology in Education (IJITE) Vol.7, No.3, September 2018

Table 2: Lecturers understanding of content for the computing disciplines

\begin{tabular}{|c|c|c|c|c|c|}
\hline $\begin{array}{l}\text { Do which computing programme would you } \\
\text { recommend a learner to take where the learner } \\
\text { is interested to work in places majoring in:- }\end{array}$ & 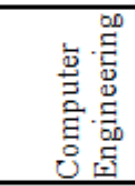 & 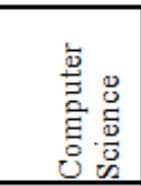 & 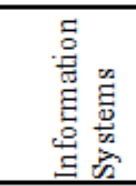 & 音 & 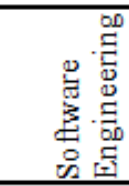 \\
\hline Computer Architecture and Organisation & $51.4 \%$ & $28.6 \%$ & $2.9 \%$ & $11.4 \%$ & $5.7 \%$ \\
\hline Platform technologies & $11.4 \%$ & $22.9 \%$ & $11.4 \%$ & $37.1 \%$ & $17.1 \%$ \\
\hline Intelligent Systems & $11.4 \%$ & $51.4 \%$ & $11.4 \%$ & $8.6 \%$ & $17.1 \%$ \\
\hline Information Management practices & $5.7 \%$ & $20.0 \%$ & $54.3 \%$ & $17.1 \%$ & $2.9 \%$ \\
\hline Numerical methods & $11.4 \%$ & $57.1 \%$ & $2.9 \%$ & $14.3 \%$ & $14.3 \%$ \\
\hline Software evolution and maintenance & $2.9 \%$ & $14.3 \%$ & $8.6 \%$ & $20.0 \%$ & $54.3 \%$ \\
\hline Distributed systems & $51.4 \%$ & $25.7 \%$ & $0.0 \%$ & $14.3 \%$ & $8.6 \%$ \\
\hline Security implementation and management & $14.3 \%$ & $17.1 \%$ & $8.6 \%$ & $48.6 \%$ & $11.4 \%$ \\
\hline Software quality & $11.4 \%$ & $14.3 \%$ & $2.9 \%$ & $14.3 \%$ & $57.1 \%$ \\
\hline Systems administration & $8.6 \%$ & $40.0 \%$ & $8.6 \%$ & $40.0 \%$ & $2.9 \%$ \\
\hline
\end{tabular}

The very correct response, indicated by the bolded percentages of placement of the courses in their most appropriate discipline from computing disciplines, lecturers chose as follows: Computer Architecture and Organisation 51.4\%, Platform technologies 37.1\%, Intelligent Systems 51.4\%, Information Management practices 54.3\%, Numerical methods 57.1\%, Software evolution and maintenance $54.3 \%$, Distributed systems $51.4 \%$, Security implementation and management $48.6 \%$, Software quality $57.1 \%$ and Systems administration $40.0 \%$. It was observed that a good portion of lecturers were not at very sure of the unique differences between the disciplines as no correct responses were generally over $80 \%$ in any one of the skill areas posed. When the responses were further subject to analysis on a scale of very correct and not very correct, the findings were as presented in figure 2.

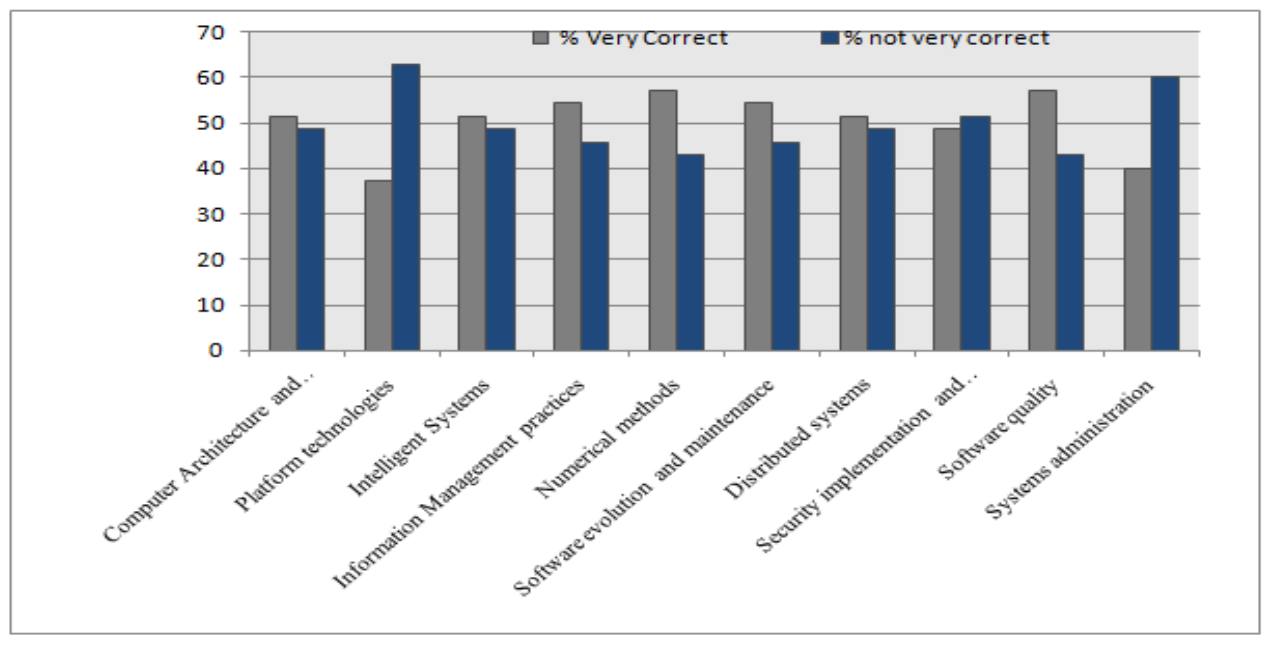

Figure 2: Percentage correct and wrong choice of computing disciplines specialty content by lecturers

From fig. 2, it can be observed that in three cases the number of lecturers who did not get the very correct placement with regard to platform technologies, security implementation and management and systems administration were more than those who gave the very correct answers. None of the very correct had a clear margin of over $60 \%$. When the very correct responses were computed against the total responses made, a percentage of $50.29 \%$ was obtained. This is just slightly above 
International Journal on Integrating Technology in Education (IJITE) Vol.7, No.3, September 2018

$50 \%$ implying that just slightly more than half of the lecturers are very clear of the differences between the computing differences.

\subsubsection{UNDERGRADUATE STUDENTS}

Thirty final year undergraduate students in computing disciplines were interviewed with regard to their understanding of the uniqueness of the computing disciplines and the findings were as presented in table 3 .

Table 3: Undergraduate Students understanding of the different computing disciplines

\begin{tabular}{|c|c|c|c|c|c|}
\hline $\begin{array}{l}\text { What qualification from the computing discipline } \\
\text { would you recommend for recruitment for an } \\
\text { organisation where the recruits duties would involve } \\
\text { majorly tasks of:- }\end{array}$ & 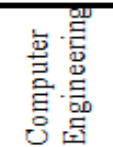 & 莺兽 & 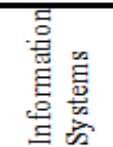 & 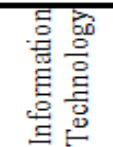 & 㟒莺 \\
\hline Algorithms & $16.7 \%$ & $60.0 \%$ & $3.3 \%$ & $6.7 \%$ & $13.3 \%$ \\
\hline Computer Architecture & $46.7 \%$ & $30.0 \%$ & $3.3 \%$ & $13.3 \%$ & $6.7 \%$ \\
\hline Operating Systems & $16.7 \%$ & $50.0 \%$ & $6.7 \%$ & $16.7 \%$ & $10.0 \%$ \\
\hline Theory of programming languages & $6.7 \%$ & $46.7 \%$ & $3.3 \%$ & $20.0 \%$ & $23.3 \%$ \\
\hline Human Computer Interaction & $6.7 \%$ & $33.3 \%$ & $3.3 \%$ & $30.0 \%$ & $26.7 \%$ \\
\hline Information Systems Development & $0.0 \%$ & $13.3 \%$ & $40.0 \%$ & $16.7 \%$ & $30.0 \%$ \\
\hline Analysis of Business requirements & $0.0 \%$ & $3.3 \%$ & $63.3 \%$ & $20.0 \%$ & $13.3 \%$ \\
\hline Software modeling and analysis & $3.3 \%$ & $30.0 \%$ & $13.3 \%$ & $13.3 \%$ & $40.0 \%$ \\
\hline Software verification & $3.3 \%$ & $13.3 \%$ & $6.7 \%$ & $20.0 \%$ & $56.7 \%$ \\
\hline Software design & $3.3 \%$ & $23.3 \%$ & $10.0 \%$ & $13.3 \%$ & $50.0 \%$ \\
\hline Computer systems Engineering & $40.0 \%$ & $20.0 \%$ & $5.7 \%$ & $8.6 \%$ & $25.7 \%$ \\
\hline Digital logic & $70.0 \%$ & $13.3 \%$ & $0.0 \%$ & $0.0 \%$ & $16.7 \%$ \\
\hline Management of Information Systems Organisation & $0.0 \%$ & $10.0 \%$ & $60.0 \%$ & $16.7 \%$ & $13.3 \%$ \\
\hline Systems Integration & $3.3 \%$ & $13.3 \%$ & $10.0 \%$ & $30.0 \%$ & $43.3 \%$ \\
\hline Technical support & $23.3 \%$ & $23.3 \%$ & $3.3 \%$ & $26.7 \%$ & $23.3 \%$ \\
\hline
\end{tabular}

The very correct response indicated by the bold percentages from Undergraduate students in computing disciplines that had have stated the correct computing discipline for a recruiting organization for Algorithms were 60.0\%, Computer Architecture were 46.7\%, Operating Systems were $50.0 \%$, Theory of programming languages were $46.7 \%$, Human Computer Interaction were $30.0 \%$, Information Systems Development were 40.0\%, Analysis of Business requirements were $63.3 \%$, Software modeling and analysis were $40.0 \%$, Software verification were $56.7 \%$, Software design were $50.0 \%$, Computer systems Engineering were $40.0 \%$, Digital logic were $70.0 \%$, Management of Information Systems Organisation were 60.0\%, Systems Integration were $30.0 \%$ and Technical support were $26.7 \%$. The observation from the findings is that Undergraduate students were not very certain of the unique differences between the disciplines since no correct responses were generally over $80 \%$ in any one of the recruitment areas suggested.

On subjecting the responses to further analysis on a scale of very correct and not very correct the results obtained were as presented in fig. 3 . 
International Journal on Integrating Technology in Education (IJITE) Vol.7, No.3, September 2018

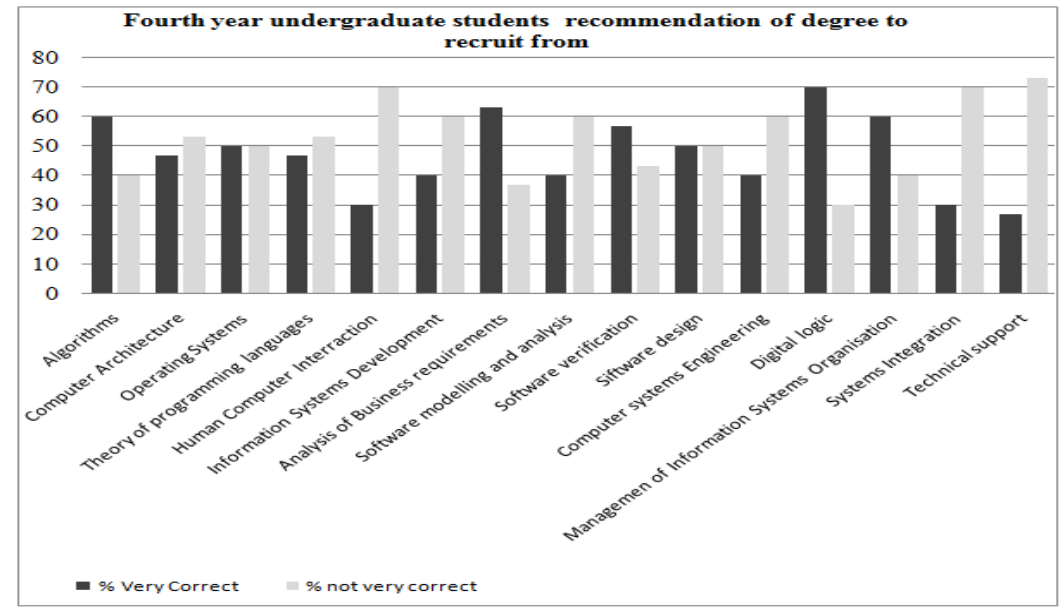

Figure 3: Percentage correct and wrong choice of computing disciplines specialty content by Undergraduate' students

From fig. 3, it was observed that in eight cases undergraduate students did not get the very correct placement on computer architecture, theory of programming languages, human computer interaction, information system development, software modeling and analysis, computer systems engineering, system integration and technical support. In the eight cases the wrong responses were more than those who gave the very correct response. It is also observable that only two cases had a clear margin of over $60 \%$.

When the very correct responses were computed against the total responses made a percentage of $47.78 \%$ was obtained. This is just slightly below $50 \%$ implying that just slightly less than half of the undergraduate students in their final year undergraduates were very clear of the differences between the computing discipline differences.

\subsubsection{BUSINESS COMMUNITY}

Thirty ICT management staff from the business community in organizations having functional computing sections within their organisations were interviewed with regard to their understanding of the uniqueness of the computing disciplines and the findings were as presented in table 4

Table 4: Business community ICT management staff understanding of uniqueness of computing disciplines

\begin{tabular}{|l|l|l|l|l|l|}
\hline $\begin{array}{l}\text { What qualification from the computing discipline } \\
\text { would you recommend for recruitment for an } \\
\text { organisation where the recruits duties would involve } \\
\text { majorly tasks of:- }\end{array}$ & & & & \\
\hline Algorithms & $13.3 \%$ & $\mathbf{6 0 . 0} \%$ & $3.3 \%$ & $6.7 \%$ & $16.7 \%$ \\
\hline Computer Architecture & $\mathbf{4 0 . 0} \%$ & $33.3 \%$ & $3.3 \%$ & $13.3 \%$ & $10.0 \%$ \\
\hline Operating Systems & $16.7 \%$ & $\mathbf{5 3 . 3} \%$ & $3.3 \%$ & $20.0 \%$ & $6.7 \%$ \\
\hline Theory of programming languages & $13.3 \%$ & $\mathbf{5 6 . 7} \%$ & $3.3 \%$ & $10.0 \%$ & $16.7 \%$ \\
\hline Human Computer Interaction & $10.0 \%$ & $20.0 \%$ & $0.0 \%$ & $\mathbf{3 0 . 0} \%$ & $40.0 \%$ \\
\hline Information Systems Development & $0.0 \%$ & $13.3 \%$ & $\mathbf{3 3 . 3} \%$ & $16.7 \%$ & $36.7 \%$ \\
\hline Analysis of Business requirements & $6.7 \%$ & $6.7 \%$ & $\mathbf{5 3 . 3} \%$ & $16.7 \%$ & $16.7 \%$ \\
\hline Software modeling and analysis & $6.7 \%$ & $30.0 \%$ & $6.7 \%$ & $13.3 \%$ & $\mathbf{4 3 . 3} \%$ \\
\hline Software verification & $0.0 \%$ & $13.3 \%$ & $6.7 \%$ & $16.7 \%$ & $\mathbf{6 3 . 3} \%$ \\
\hline Software design & $6.7 \%$ & $20.0 \%$ & $6.7 \%$ & $13.3 \%$ & $\mathbf{5 3 . 3} \%$ \\
\hline Computer systems Engineering & $\mathbf{5 3 . 3} \%$ & $20.0 \%$ & $3.3 \%$ & $6.7 \%$ & $16.7 \%$ \\
\hline Digital logic & $\mathbf{7 0 . 0} \%$ & $6.7 \%$ & $3.3 \%$ & $6.7 \%$ & $13.3 \%$ \\
\hline Management of Information Systems Organisation & $0.0 \%$ & $20.0 \%$ & $\mathbf{6 3 . 3} \%$ & $16.7 \%$ & $0.0 \%$ \\
\hline Systems Integration & $3.3 \%$ & $33.3 \%$ & $10.0 \%$ & $\mathbf{3 6 . 7 \%}$ & $16.7 \%$ \\
\hline Technical support & $30.0 \%$ & $30.0 \%$ & $3.3 \%$ & $\mathbf{2 0 . 0} \%$ & $16.7 \%$ \\
\hline
\end{tabular}


The very correct response as indicated by the bold percentages obtained from ICT management staff in business community were Algorithms $60.0 \%$, Computer Architecture 40.0\%, Operating Systems 53.3\%, Theory of programming languages 56.7\%, Human Computer Interaction $30.0 \%$, Information Systems Development 33.3\%, Analysis of Business requirements 53.3\%, Software modeling and analysis $43.3 \%$, Software verification $63.3 \%$, Software design 53.3\%, Computer systems Engineering 53.3\%, Digital logic 70.0\%, Management of Information Systems Organisation $63.3 \%$, Systems Integration $36.7 \%$ and Technical support $20.0 \%$. The observation from the findings is that ICT management staff were not very certain of the unique differences between the disciplines since no correct responses were over $80 \%$.

When the findings were further analysed based on a scale of very correct and not very correct, the results were as presented in fig. 4 .

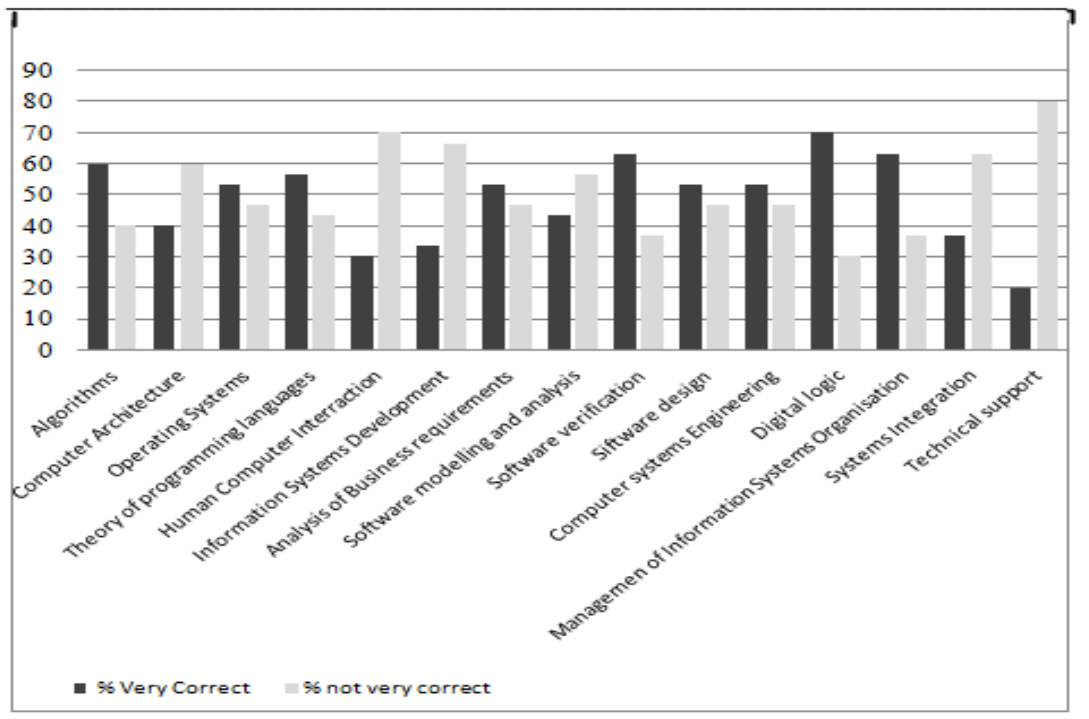

Figure 4: Percentage correct and wrong choice of computing disciplines specialty content by business community ICT management staff

From fig. 4, it can be observed that in six cases, the number of ICT management staff who did not get the very correct placement (computer architecture, human computer interaction, information system development, software modeling and analysis, system integration and technical support) were more than those who gave the very correct answers. In cases where they gave a very correct placement, only three cases were with a clear margin of over $60 \%$.

When the very correct responses were computed against the total responses made a percentage of $48.67 \%$ was obtained. This is just slightly below $50 \%$ implying that just slightly less than half of the ICT managers are very clear of the differences between the computing differences. However, the percentage is slightly better than that of undergraduate final year students. This could be due to their exposure while working. This basically calls for the need to equip computing students while at undergraduate to understand the differences between the computing disciplines and hence which career is best suited for each discipline.

\subsection{ACADEMIC LEADERSHIP OF COMPUTING DisCIPLINES IN KENYA}

Commission for University Education from 2012 has provided clear leadership as regards to whom and when a given institution can offer a given program. According to the Commission for University Education standard PROG/STD/17 with regard to university staff, any academic programme has to adhere to the following:- 
International Journal on Integrating Technology in Education (IJITE) Vol.7, No.3, September 2018

(i) An academic programme shall be supported by adequate full-time staff holding requisite academic qualifications.

(ii) A programme shall be guided by appropriately qualified academic leader.

\section{The standard is the operationalised by the guidelines that require amongst others that:}

(i) Each academic programme shall be headed by a full-time appropriate and qualified Senior Lecturer and above with at least five (5) years university teaching experience, who shall hold a doctorate degree in the relevant disciplines of study;

(ii) Each academic programme shall be supported by at least two (2) other appropriate full-time academic staff members;

For this reason, the study sought to know how $\mathrm{PhD}$ holders in computing disciplines were distributed to provide the leadership. Table 5 provides the findings. The study used only $\mathrm{PhD}$ holders within the computing disciplines since it was not possible to ascertain from the university website their experience as well as ranks of the staff

\begin{tabular}{|c|c|c|c|c|c|c|}
\hline & University & 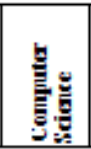 & 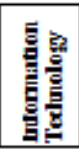 & 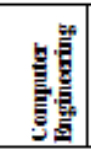 & 镸 & 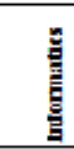 \\
\hline \multicolumn{7}{|c|}{ Public Chartered Universities } \\
\hline 1 & University of Nairobi & $38.1 \%$ & $0.0 \%$ & $25.0 \%$ & $23.5 \%$ & $0.0 \%$ \\
\hline 2 & Moi University & $9.5 \%$ & $0.0 \%$ & $0.0 \%$ & $59 \%$ & $0.0 \%$ \\
\hline 3 & Kenyatta University & $4.8 \%$ & $0.0 \%$ & $0.0 \%$ & $59 \%$ & $0.0 \%$ \\
\hline 4 & Egerton University & $0.0 \%$ & $0.0 \%$ & $25.0 \%$ & $0.0 \%$ & $50.0 \%$ \\
\hline 5 & Maseno University & $0.0 \%$ & $10.0 \%$ & $25.0 \%$ & $0.0 \%$ & $0.0 \%$ \\
\hline 6 & Dedan Kimathi University of Technology & $9.5 \%$ & $0.0 \%$ & $0.0 \%$ & $0.0 \%$ & $0.0 \%$ \\
\hline 7 & Pwani University & $4.8 \%$ & $0.0 \%$ & $0.0 \%$ & $0.0 \%$ & $0.0 \%$ \\
\hline 8 & $\begin{array}{l}\text { Jaramogi Oginga Odinga Univ. of Science and } \\
\text { Tech. }\end{array}$ & $4.8 \%$ & $0.0 \%$ & $0.0 \%$ & $17.6 \%$ & $0.0 \%$ \\
\hline 9 & Masinde Muliro Univ. of Science and Tech. & $0.0 \%$ & $10.0 \%$ & $0.0 \%$ & $59 \%$ & $0.0 \%$ \\
\hline 10 & Maasai Mara University & $0.0 \%$ & $0.0 \%$ & $0.0 \%$ & $0.0 \%$ & $0.0 \%$ \\
\hline 11 & Laikipia University & $0.0 \%$ & $10.0 \%$ & $0.0 \%$ & $0.0 \%$ & $0.0 \%$ \\
\hline 12 & University of Kabianga & $0.0 \%$ & $10.0 \%$ & $0.0 \%$ & $0.0 \%$ & $0.0 \%$ \\
\hline 13 & Kibabii University & $4.8 \%$ & $40.0 \%$ & $25.0 \%$ & $0.0 \%$ & $0.0 \%$ \\
\hline 14 & Chuka University & $0.0 \%$ & $0.0 \%$ & $0.0 \%$ & $0.0 \%$ & $0.0 \%$ \\
\hline 15 & Embu University & $4.8 \%$ & $0.0 \%$ & $0.0 \%$ & $11.8 \%$ & $0.0 \%$ \\
\hline 16 & Technical University of Renya & $4.8 \%$ & $10.0 \%$ & $0.0 \%$ & $59 \%$ & $0.0 \%$ \\
\hline \multirow[t]{2}{*}{17} & Technical University of Mombasa & $0.0 \%$ & $0.0 \%$ & $0.0 \%$ & $0.0 \%$ & $0.0 \%$ \\
\hline & Total in public chartered universities & $85.7 \%$ & $90.09 \%$ & $100.0 \%$ & $76.5 \%$ & $50.09 \%$ \\
\hline \multicolumn{7}{|c|}{ Private chartered universities } \\
\hline 1 & University of Eastem Africa, Baraton & $0.0 \%$ & $0.0 \%$ & $0.0 \%$ & $0.0 \%$ & $0.0 \%$ \\
\hline 2 & Catholic University of Eastem Africa & $0.0 \%$ & $0.0 \%$ & $0.0 \%$ & $0.0 \%$ & $0.0 \%$ \\
\hline 3 & Daystar University & $0.0 \%$ & $0.0 \%$ & $0.0 \%$ & $0.0 \%$ & $0.0 \%$ \\
\hline 4 & United States Intemational University & $48 \%$ & $0.0 \%$ & $0.0 \%$ & $17.6 \%$ & $0.0 \%$ \\
\hline 5 & Pan Africa Christian University & $0.0 \%$ & $0.0 \%$ & $0.0 \%$ & $0.0 \%$ & $0.0 \%$ \\
\hline 6 & Africa Intemational University & $0.0 \%$ & $0.0 \%$ & $0.0 \%$ & $0.0 \%$ & $0.0 \%$ \\
\hline 7 & Strathmore University & $9.5 \%$ & $10.0 \%$ & $0.0 \%$ & $59 \%$ & $50.0 \%$ \\
\hline & Total in private chartered universities & $14,3 \%$ & $10.0 \%$ & $0.0 \%$ & $23.5 \%$ & $50.09 \%$ \\
\hline
\end{tabular}

Table 5: Doctorate holders distribution for leadership in computing disciplines

Source: [14] Data collected from respective university websites as at 01/04/2018

Table 5 indicates that $\mathrm{PhD}$ holders in Computer Science who are capable of providing basic leadership needed for undergraduate programmes are distributed amongst public chartered universities. University of Nairobi had 38.1\%, Moi University had 9.5\%, Kenyatta University had 4.8\%, Dedan Kimathi University of Technology had 9.5\%, Pwani University had 4.8\%, Jaramogi Oginga Odinga University of Science and Technology had 4.8\%, Kibabii University had $4.8 \%$, Embu University had $4.8 \%$, and Technical University of Kenya had $4.8 \%$ with the total in public 
International Journal on Integrating Technology in Education (IJITE) Vol.7, No.3, September 2018

chartered universities being $85.7 \%$. On the other hand within the private chartered universities there were United States International University 4.8\%, Strathmore University 9.5\% with the total in private chartered universities being $14.3 \%$.

Table 5 indicates that there is no single $\mathrm{PhD}$ holder in software Engineering in both public and private chartered university involved in the study.

The doctorate holders in Computer Engineering in public chartered universities hence basic leadership for undergraduate programmes in the specialty as follows: University of Nairobi $25.0 \%$, Egerton University $25.0 \%$, Maseno University $25.0 \%$, and Kibabii University $25.0 \%$ with the public universities taking in total $100 \%$. No private chartered university in the study had staff at the level of $\mathrm{PhD}$ in this field

In Information Systems, the distribution of PhD staff was University of Nairobi 23.5\%, Moi University $5.9 \%$, Kenyatta University $5.9 \%$, Jaramogi Oginga Odinga Univ. of Science and Technology 17.6\%, Masinde Muliro Univ. of Science and Technology 5.9\%, Embu University $11.8 \%$, Technical University of Kenya $5.9 \%$ with the public chartered universities taking a total of $76.5 \%$. From the private chartered universities there was United States International University $17.6 \%$, Strathmore University $5.9 \%$ hence the total in private chartered universities being $23.5 \%$.

From table 5 its notable that PhD holders in Information Technology, basic leadership needed for undergraduate programmes were distributed such that Maseno University had $10.0 \%$, Masinde Muliro University of Science and Technology $10.0 \%$, Laikipia University $10.0 \%$, University of Kabianga $10.0 \%$, Kibabii University $40.0 \%$, Technical University of Kenya $10.0 \%$ with the total for public chartered universities being $90.0 \%$. From the private chartered universities, there was only Strathmore University with $10.0 \%$ of the whole total.

However, it was observed that mobility of lecturers in computing fields is so high for those who held $\mathrm{PhD}$ qualification and the statistics may also change so frequently from one university to another.

\section{SUMMARY AND CONCLUSION}

With regard to review of uniqueness of computing disciplines, the study established that six distinct computing specialties have evolved over the period with the latest to emerge being Information and Communication Technology. Each of the computing academic discipline has a primary focus area as follows:

(a) Computer Science is the study of computing theory. It is concerned with answering the question, "what is a computer system capable of doing?" or "can our computer system do this?" It views computing from a broad, scientific basis, focusing on developing effective ways to solve computing problems, devising new ways to use computers, and designing and implementing software ("programming").

(b) Information Systems is the study of meeting the practical computing needs of a business, with an emphasis on information. It focuses on getting the maximum business impact out of the implementation of a system. Information Systems focuses on the "information" aspects of "information technology".

(c) Information Technology is the study of meeting the computing needs of a business, with an emphasis on technology. It focuses on answering the question, "what technologies are available and how can we reliably implement and integrate them with our existing systems?"

(d) Software Engineering is the study of building software that meets the needs of the customer on time and within budget. Software Engineering focuses on developing and maintaining software systems (particularly large, complex systems) that behave reliably and efficiently that are affordable to develop and maintain. 
International Journal on Integrating Technology in Education (IJITE) Vol.7, No.3, September 2018

(e) Computer Engineering is the study of the design of the machine, its components, and peripheral devices. Computer Engineering focuses on the design and construction of computers and computer-based systems/devices (i.e., hardware and related software).

(f) Information Communication Technology study that involves the convergence of information technology (IT), telecommunication, and management and business with emphases in Networking, Media, Technical communications, Web management, Enterprise systems and Leadership development in meeting the needs of a business.

The second objective of the study was to determine the stakeholders understanding of the skills for each of the computing disciplines. The study found out that some stakeholders understood the skills of each of the computing disciplines; some did not clearly understand the difference between the different computing disciplines. A fraction of the practicing ICT professionals did not know the difference between the disciplines.

From the observation made from table 5, it is apparent that 14 public chartered universities of the total 17 in the study had basic undergraduate program leadership while 2 of the 7 private chartered universities had basic undergraduate program leadership. This represents on the overall $69.23 \%$ of the public and $33.33 \%$ private chartered universities having leadership towards computing degree programmes. The universities from which the statistics have been obtained constituted $56.52 \%$ and $52.94 \%$ of the public and private chartered universities in Kenya. The public chartered universities had better percentages across the board for provision leadership to degree programmes in computing disciplines.

A clear understanding of the differences within the computing disciplines will lead to the industry employing the most appropriate skills needed for a given task hence reducing the costs of having to retrain the employees. On the other hand, lack of understanding the discipline differences would lead to a possibility of professionals performing tasks for which they are not best skilled to. Equally, employers may not be getting the best return on their investment resulting from not hiring the most appropriate skill from within the computing disciplines. A clear understanding of the differences between the computing disciplines would enable the learners to choose the most appropriate computing training. Finally, it will enable trainers to provide the most appropriate curriculum skills training and developing the most appropriate programme leadership that would result in producing the best suited graduates of the unique programmes to best meet to unique needs of the market demands.

\section{REFERENCES}

[1] Courte J. \& Bishop-Clark, C. (2009). Do students differentiate between computing disciplines? ACM Sigcse Bulletin. 41. 29-33. 10.1145/1539024.1508877.

[2] Brandenburg, Marcus and Dudt, Kurt (1998) "International Education" in Classroom communication and ICT integration: public high school teachers' notions. International Journal on Integrating Technology in Education (IJITE) 4 (2):1-11 DOI: 10.5121/ijite.2015.4201

[3] Lachica L. P. F. (2015). Classroom communication and ICT integration: public high school teachers' notions. International Journal on Integrating Technology in Education (IJITE) 4 (2):1-11 DOI: $10.5121 /$ ijite.2015.4201

[4] Lunt M. B. and Ekstrom K. J. (2008). What Distinguishes Each of the Major Computing Disciplines? Sixth LACCEI International Latin American and Caribbean Conference for Engineering and Technology (LACCEI'2008) "Partnering to Success: Engineering, Education, Research and Development" June 4 - June 6 2008, Tegucigalpa, Honduras

[5] Shackelford R, Cross J, Davies G, Impagliazzo J, Kamali R, LeBlanc R, Lunt B, McGettrick, A.D, Sloan R and Topi H. (2004) CE 2004: Computer engineering: curriculum guidelines for undergraduate degree programmes in computer engineering. IEEE. 
International Journal on Integrating Technology in Education (IJITE) Vol.7, No.3, September 2018

[6] Wabwoba F. \& Ikoha A. P. (2011). Information Technology research in developing nations: Major research methods and publication outlets. International Journal of Information and Communication Technology Research. 1 (6): 253-257.

ISSN 2223-4985 www.collegeboard.com/csearch/majors_careers/profiles/majors/52.1201.html

[7] Computer Engineering Curricula 2016. Curriculum Guidelines for Undergraduate Degree Programs in Computer Engineering. A Report in the Computing Curricula Series of the Joint Task Group on Computer Engineering Curricula by the Association for Computing Machinery (ACM) and IEEE Computer Society Version 2015 October 25

[8] Computer Science Curricula 2013. Curriculum Guidelines for Undergraduate Degree Programs in Computer Science December 20, 2013 of the Joint Task Force on Computing Curricula of the Association for Computing Machinery (ACM) and IEEE Computer Society

[9] Computing Curricula 2005 The Overview Report covering undergraduate degree programs in Computer Engineering Computer Science Information Systems Information Technology Software Engineering. A volume of the Computing Curricula Series of the Joint Task Force for Computing Curricula 2005, A cooperative project of The Association for Computing Machinery (ACM), The Association for Information Systems (AIS) and The Computer Society (IEEE-CS) of 30 September 2005

[10] Topi H., Valacich J. S, Wright R. T, Kaiser K. M, Nunamaker Jr J.F, Sipior J. C and de Vreede G.J (2010). IS 2010 Curriculum Guidelines for Undergraduate Degree Programs in Information Systems. Association for Computing Machinery (ACM) and Association for Information Systems (AIS)

[11] Information Technology Curricula 2017. Curriculum Guidelines for Baccalaureate Degree Programs in Information Technology. A Report in the Computing Curricula Series of the Task Group on Information Technology Curricula by Association for Computing Machinery (ACM) and IEEE Computer Society (IEEE-CS) 2017 December 10

[12] Lunt B.M., Ekstrom J. J., Gorka S., Hislop G., Kamali R., Lawson E., LeBlanc R., Miller J., \& Reichgelt H. (eds.) (2008). Information Technology 2008: Curriculum Guidelines for Undergraduate Degree Programs in Information Technology, Association of Computing Machinery (ACM), IEEE Computing Society (IEEE-CS).

[13] Software Engineering 2014 Curriculum Guidelines for Undergraduate Degree Programs in Software Engineering. A Volume of the Computing Curricula Series 23 February 2015 of the Joint Task Force on Computing Curricula of IEEE Computer Society and Association for Computing Machinery

[14] Website of all charter universities in Kenya as at 01/04/2018

\section{AUTHORS}

Nambiro Alice Wechuli received the Bachelor of Science degree in Computer Science from Masinde Muliro University of Science and Technology, Master of Science degree in Information Technology from the same University and Doctor of Philosophy degree in Information Technology from Kibabii University. She is a lecturer in the Department of Information Technology at Kibabii University, Kenya. Her research interests include data and information management and system security. She is a member of the International Association of Engineers (IAENG).

Prof. Franklin Wabwoba is an Associate Professor of Information Technology and Dean of the School of Computing and Informatics at Kibabii University (Kenya). He holds a Doctor of Philosophy degree in Information Technology from Masinde Muliro University of Science and Technology, Master of Science (Computer Applications) from Kenyatta University; Endorsement (Educational Management) from University of South Africa and Bachelor of Education (science: Mathematics and Computer

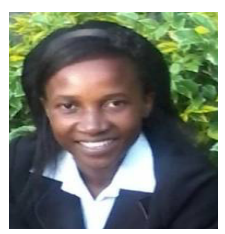
Science) from Egerton University. He has taught Computer Science and Information Technology courses for many years. He has ICT industrial experience having worked with Mumias Sugar Company. He has presented several papers in scientific conferences and has many publications in referred journals as well as university level computing books. He has a strong research interest in green ICT, the impact of ICT applications on the community and integration of ICT into education. He is a professional member of the Association for Computing Machinery (ACM) and the International Association of Engineers (IAENG). 